\title{
Comparison of Different Risk Factors and Coronary Angiographic Profile in Younger and Older Patients with Ischeamic Heart Disease
}

\author{
Kazi Nazrul Islam ${ }^{1}$, Abdul Wadud Chowdhury ${ }^{1}$, Azizul Hasan Khandaker ${ }^{2}$, Khandker Md. Nurus \\ Sabah $^{1}$, Md. Gaffar Amin ${ }^{1}$, Syed Rezwan Kabir ${ }^{1}$, Mohammed Abaye Deen Saleh ${ }^{1}$. \\ ${ }^{1}$ Department of Cardiology, Dhaka Medical College,Dhaka. ${ }^{2}$ Upazilla Health Complex, \\ Adamdighi, Bogra
}

Key Words : Ischaemic heart disease, Risk factors, Coronary angiography.

\begin{abstract}
:
Background: Due to socio-economic improvement and changes in the life style, ischeamic heart disease is becoming a major burden to our health care system. In recent years, the incidence is increasing among younger age groups as well.

Methods: A total of 120 patients with ischeamic heart disease admitted for coronary angiogram were included in the study and were divided into two groups. Among them, 60 younger patients were in Group-I (d" 40 years of age); 60 older patients in Group-II (>40 years of age). We compared demographic profiles, different risk factors and angiographic profiles between two age groups.

Results: Among the common risk factors, smoking $(63.3 \%$ vs 40\%, p=0.011) \& family history of ischeamic heart disease $(21.7 \%$ vs $8.3 \%, p=0.040)$ were more common in younger group. Whereas, hypertension $(41.7 \%$ vs $65.0 \%, p=0.010)$ and $D M(18.3 \%$ vs $36.7 \%, p=0.024)$ were more common in older patients. Serum Homocysteine level was found significantly higher in younger patients (30.0\% vs $13.3 \%, p=0.026$ ). In group-I. coronary angiography revealed normal coronaries in 15 patients (25\%), single vessel disease in $29(48.3 \%)$ and multi-vessel disease in 16 patients (26.6\%). Whereas, $40(66.6 \%)$ patients in group-II were found to have multi-vessel disease and 2 of them had significant left main coronary disease. However, young patients who had high serum homocysteine level showed more angiographic severity than older patients.

Conclusion: There are significant differences in the clinical, biochemical and angiographic profile of young patients with ischeamic heart disease as compared to older patients. Young patients with ischeamic heart disease has got less angiographic severity, except in those with high serum homocysteine level.
\end{abstract}

(Cardiovasc. j. 2015; 8(1): 23-29)

\section{Introduction:}

Ischaemic heart disease (IHD) is a disease of the heart muscle resulting from ischaemia. The term IHD is generally applied only to cases of atherosclerotic origin. ${ }^{1}$ Acute myocardial infarction (AMI) is an uncommon entity in the young, but it constitutes an important problem for such patients and their treating physician because of its devastating effect on their more active life. ${ }^{2}$ Over all $4-8 \%$ of the patients with AMI are less than 40 years of age. ${ }^{3}$ The cause of MI among patients in younger age group can be divided into four groups; atheromatous coronary artery disease, non atheromatous coronary disease, hypercoagulable states and MI related to substance abuse. ${ }^{4}$
Traditionally there are some conventional risk factors like age, male sex, family history of premature cardiovascular disease, hypertension, smoking, dyslipidemia, metabolic syndrome, diabetes mellitus (DM), lack of exercise, obesity and some emerging risk factors like C-Reactive Protein, Homocysteine, Fibrinogen. Lipoprotein(a), which are considered important for IHD. Control of different risk factors for IHD is important as it is associated with decreased mortality and morbidity. ${ }^{5}$

There are many studies done in Bangladesh and abroad regarding the pattern of coronary angiogram in different settings. But few studies were done regarding angiographic profile of

Address of Correspondence: Dr. Kazi Nazrul Islam, Department of Cardiology, Dhaka Medical College,Dhaka, Bangladesh. Email- kazinazrul69@gmail.com. 
patients with IHD (i.e. chronic stable angina, ST elevated myocardial infarction (STEMI), Non-ST elevated myocardial Infarction (NSTEMI) and unstable angina (UA)] in those $\leq 40$ years. This study was performed to determine the coronary angiographic profile in young and older patients with IHD and its correlation with conventional and emerging coronary risk factors.

\section{Methods:}

This cross sectional observational study has been carried out in the Department of Cardiology, Dhaka Medical College Hospital from October 2009 to September 2010. A total of 120 IHD (chronic stable angina, UA, STEMI and NSTEMI patients admitted for CAG were divided into two groups. 60 patients in group- $\mathrm{I} \leq 40$ years of age; and 60 patients in group- II $>40$ years of age. Purposive sampling method was followed as per inclusion and exclusion criteria. Informed consent was taken from each patient who fulfills the criteria. Initial evaluation of the patients by history and clinical examination was done and recorded in a preformed data collection sheet. Baseline laboratory investigations were done for each patient. Age, sex, hypertension, DM, dyslipidaemia, smoking, family history of premature IHD, obesity (defined by BMI), left Ventricular Hypertrophy (LVH) [assessed by echocardiography] and serum homocysteine were measured. Fasting serum homocysteine was measured in each patient by Fluorescence Polarization Immuno-assay [FPIA] detection method. CAG was done by transfemoral route by Judkin's Catheter. Angiographic pattern and severity of coronary artery disease was assessed by (a) Vessel score: (b) Friesinger score: and (C) Type of coronary lesions. Data were analyzed by using Statistical package for Social Science (SPSS) and MS Excel software.

\section{Results:}

In this study, the mean age was $35.4 \pm 4.2$ years and $53.7 \pm 7.3$ years in group I and group II respectively. It was observed that in group I, 78.3\% was male and rest $21.7 \%$ was female. In group II, $73.3 \%$ was male and $26.7 \%$ was female. Mean BMI $24.3 \pm 7.3 \mathrm{~kg} / \mathrm{m} 2$ in group I and $25.0 \pm 8.2 \mathrm{~kg} / \mathrm{m} 2$ in group II. Smoker was found $63.3 \%$ in group I and $40.0 \%$ in group II. Hypertension was found $41.7 \%$ in group I and $65.0 \%$ in group II. DM was found $18.3 \%$ in group I and $36.7 \%$ in group II. Dyslipidaemia was found $85.0 \%$ and $73.3 \%$ in group I and group II respectively. Family history of premature IHD was found $21.7 \%$ in group I and $8.3 \%$ in group II. $16.7 \%$ and $35.0 \%$ patients had LVH (on echo criteria) in group I and group II. It was also found that $30.0 \%$ and $13.3 \%$ had high serum homocysteine level $(>15 \mu \mathrm{mol} / \mathrm{L})$ in group I and group II respectively (Table-I).

\section{Table-I}

Clinical characteristics of study patients $(n=120)$.

\begin{tabular}{lccc}
\hline Variables & Group -I (n=60) & Group -II (n=60) & p value \\
\hline Mean Age (yrs)** & $35.40 \pm 4.20$ & $53.70 \pm 7.30$ & \\
Male (n /\%) & $47(78.30 \%)$ & $44(73.30 \%)$ & \\
Female (n /\%) & $13(21.70 \%)$ & $16(26.70 \%)$ & 0.522 \\
Mean BMI (Kg/m2)** & $24.30 \pm 7.30$ & $25.60 \pm 8.20$ & 0.955 \\
Smoking (n / \%)* & $38(63.30 \%)$ & $24(40.00 \%)$ & 0.011 \\
Hypertension (n / \%)* & $25(41.70 \%)$ & $39(65.00 \%)$ & 0.010 \\
DM(n / \%)* & $11(18.30 \%)$ & $22(36.70 \%)^{\mathrm{NS}}$ & 0.024 \\
Dyslidaemia (n / \%)* & $51(85.00 \%)$ & $44(73.30 \%)$ & 0.115 \\
F/H IHD (n / \%)* & $13(21.70 \%)$ & $5(8.30 \%)$ & 0.040 \\
LVH(on echo criteria)* & $10(16.70 \%)$ & $21(35.00 \%)$ & 0.021 \\
Hyperhomocystenemia* & $18(30.00 \%)$ & $8(13.30 \%)$ & 0.026 \\
\hline
\end{tabular}

$\mathrm{BMI}=$ Basal Metabolic Index, F/H IHD = Family History of premature Ischeamic Heart Disease, LVH= Left Ventricular Hypertrophy* ${ }^{*}$ hi-square test was done and $p<0.05$ taken as level of significance. ${ }^{* * i n d e p e n d e n t ~ s a m p l e ~ t e s t ~}$ 
Coronary angiogram profile of the study population showed that normal vessel was present more in group I than group II $(30.9 \%$ vs $7.8 \%, \mathrm{p}=0.022)$. Similarly, single vessel disease (SVD) was more in group I than group II $(50.0 \%$ vs $23.0 \%, \mathrm{p}=0.007)$. However, Double (DVD) and triple vessel diseases (TVD) were found more in group II than group I $(38.3 \%$ vs $18.3 \%, \mathrm{p}=0.015)$ and $(28.3 \%$. vs $8.3 \%$, $\mathrm{p}=0.004)$ respectively (Table-II).

Regarding the involvement of vessels, Left Main (LM) disease was not found in group I but 3.3\% had LM disease in group II. Left anterior descending (LAD) $33.3 \%$ vs $70.0 \%$ was the most commonly involved vessel followed by right coronary artery (RCA) $31.7 \%$ vs $61.7 \%$ and left circumflex artery (LCX) $30.0 \%$ vs $30.0 \%$ in both groups. Normal coronary arteries were significantly higher in group I patients (Table- III).

It was also observed that Friesinger score $0-4$ (i.e. less extensive disease) was predominant in group I ( $73.3 \%$ vs $33.3 \%, \mathrm{p}=0.001)$. Friesinger score $\geq 5$ (i.e. more extensive disease) was predominant in group II ( $26.7 \%$ vs $66.7 \%$, p=0.001) (Table- IV).

In our study we observed that prominently type A lesions in groups I and type B lesions in group II (Table-V).
With normal serum homocysteine level, younger patients had more SVD or normal coronaries, but older patients even with normal homocysteine level had more double or triple vessel disease (Table-VI).

However, when we consider hyperhomocystenemia, the advantage of younger age group is lost. With high serum homocysteine, younger age groups have less normal coronaries $(11.1 \%$ vs $25.0 \%, p=0.359$ ), The advantage of younger age in group I also become statistically insignificant regarding double or triple vessel involvement (Table- VII).This shows that hyperhomocystenemia to some extent erase the advantage of age difference between younger and older age groups, regarding number of coronary vessel involved.

When assessing extent of CAD by Friesinger score, younger patients with normal homocysteine level have low score $(<5)$ compared with older group (83.3\% vs16.7\%); but with hyperhomocysteinemia they have mostly high Friesinger score $(\geq 5)$ (38.90\% vs $61.10 \%$ ) indicating more extensive CAD. Older CAD patients however showed higher Friesinger score in both normal homocysteine group (30.80\% vs $69.20 \%)$ and hyperhomocysteinemia group (50\% vs $50 \%$ ) suggesting no correlation between level of serum homocysteine and extent of CAD in older age group(Table- VIII ).

Table-II

Comparative analysis of angiographic profile between younger and older IHD patients $(n=120)$.

\begin{tabular}{|c|c|c|c|c|c|c|}
\hline \multirow[t]{2}{*}{ Vesselscore } & \multirow[t]{2}{*}{ No of vessel } & \multicolumn{2}{|c|}{ Group I $(n=60)$} & \multicolumn{2}{|c|}{ Group II $(n=60)$} & \multirow[t]{2}{*}{$\mathrm{p}$ value } \\
\hline & & $\mathrm{N}$ & $\%$ & $\mathrm{~N}$ & $\%$ & \\
\hline 0 & Normal coronary artery* & 15 & 25.0 & 5 & 8.3 & 0.022 \\
\hline 1 & SVD* & 29 & 48.3 & 15 & 25.0 & 0.007 \\
\hline 2 & DVD* & 11 & 18.3 & 23 & 38.3 & 0.015 \\
\hline 3 & TVD* & 5 & 8.3 & 17 & 28.3 & 0.004 \\
\hline
\end{tabular}

*Chi-square test was done and $\mathrm{p}<0.05$ taken as level of significance

Table-III

Comparison of groups according to involvement of vessels $(n=120)$.

\begin{tabular}{lcccccc}
\hline Coronary Vessel & \multicolumn{2}{c}{ Group I $(\mathrm{n}=60)$} & & \multicolumn{2}{c}{ Group II $(\mathrm{n}=60)$} & $\mathrm{p}$ value \\
\cline { 2 - 3 } Involvement & $\mathrm{N}$ & $\%$ & & $\mathrm{~N}$ & $\%$ & \\
\hline $\mathrm{LM}^{*}$ & 0 & 0 & 2 & 3.3 & 0.247 \\
$\mathrm{LAD}^{* *}$ & 20 & 33.3 & & 42 & 70.0 & 0.001 \\
$\mathrm{LCX}$ & 18 & 30 & 34 & 56.7 & 0.001 \\
RCA & 19 & 31.7 & & 37 & 61.7 & 0.001 \\
Normal & 15 & 25 & 5 & 8.3 & 0.014 \\
\hline
\end{tabular}

${ }^{*}$ P v value reached from Fisher's exact test.

${ }^{* *}$ Chi-square test was done and $\mathrm{p}<0.05$ taken as level of significance. 


\section{Table-IV}

Comparative study of severity of coronary artery disease assessed by Friesinger score between two groups $(n=120)$.

\begin{tabular}{|c|c|c|c|c|c|}
\hline \multirow[t]{2}{*}{ Friesinger score } & \multicolumn{2}{|c|}{ Group I $(n=60)$} & \multicolumn{2}{|c|}{ Group II(n=60) } & \multirow[t]{2}{*}{$\mathrm{p}$ value } \\
\hline & $\mathrm{N}$ & $\%$ & $\mathrm{~N}$ & $\%$ & \\
\hline 0-4(less extensive CAD)* & 44 & 73.3 & 20 & 33.3 & 0.001 \\
\hline$\geq 5(\text { more extensive } \mathrm{CAD})^{*}$ & 16 & 26.7 & 40 & 66.7 & 0.001 \\
\hline
\end{tabular}

${ }^{*}$ Chi-square test was done and $\mathrm{p}<0.05$ taken as level of significance, CAD- Coronary artery disease.

Table-V

Comparative analysis of type of lesions of the younger and older IHD patients $(n=120)$.

\begin{tabular}{|c|c|c|c|c|}
\hline \multirow[t]{2}{*}{ Type of Coronary lesions } & \multicolumn{2}{|c|}{ Group I (n=60) } & \multicolumn{2}{|c|}{ Group II $(\mathrm{n}=60)$} \\
\hline & $\overline{\mathrm{N}}$ & $\%$ & $\mathrm{~N}$ & $\%$ \\
\hline \multicolumn{5}{|c|}{ Left anterior descending artery } \\
\hline Type A & 14 & 31.8 & 16 & 29.1 \\
\hline Type B & 4 & 9.1 & 18 & 32.7 \\
\hline Type C & 2 & 4.5 & 7 & 12.7 \\
\hline \multicolumn{5}{|l|}{ Left circumflex artery } \\
\hline Type A & 14 & 31.8 & 11 & 20 \\
\hline Type B & 2 & 4.5 & 14 & 25.5 \\
\hline Type C & 2 & 4.5 & 8 & 14.5 \\
\hline \multicolumn{5}{|l|}{ Right coronary artery } \\
\hline Type A & 12 & 27.3 & 10 & 18.2 \\
\hline Type B & 3 & 6.8 & 17 & 30.9 \\
\hline Type C & 2 & 4.5 & 9 & 16.4 \\
\hline \multicolumn{5}{|l|}{ Left Main artery } \\
\hline Type B & - & - & 2 & 3.6 \\
\hline
\end{tabular}

Table-VI

Comparison of angiographic profile of study population with normal serum homocysteine patients $(n=94)$.

\begin{tabular}{llcccccc}
\hline Vessel Score & No of Vessel & \multicolumn{2}{c}{ Group I $(\mathrm{n}=42)$} & & \multicolumn{2}{c}{ Group II $(\mathrm{n}=52)$} & p Value \\
& & $\mathrm{N}$ & $\%$ & & $\mathrm{~N}$ & $\%$ & \\
\hline 0 & Normal coronary artery & 13 & 30.9 & & 7.8 & 0.001 \\
1 & SVD & 21 & 50.0 & & 12 & 23.0 & 0.007 \\
2 & DVD & 6 & 14.3 & & 21 & 40.4 & 0.005 \\
3 & TVD & 2 & 4.8 & & 16 & 30.8 & 0.001 \\
\hline
\end{tabular}

$\mathrm{p}$ value reached from chi square test 
Table-VII

Comparison of angiographic profile of study population with to hyperhomocystenemia $(n=26)$.

\begin{tabular}{|c|c|c|c|c|c|c|}
\hline \multirow{2}{*}{$\begin{array}{l}\text { Vessel } \\
\text { score }\end{array}$} & \multirow[t]{2}{*}{ No of vessel } & \multicolumn{2}{|c|}{ Group I $(n=18)$} & \multicolumn{2}{|c|}{ Group II $(n=8)$} & \multirow[t]{2}{*}{$\mathrm{p}$ Value } \\
\hline & & $\mathrm{N}$ & $\%$ & $\mathrm{~N}$ & $\%$ & \\
\hline 0 & Normal coronary artery & 2 & 11.1 & 2 & 25.0 & 0.359 \\
\hline 1 & Single vessel disease (SVD) & 10 & 55.5 & 1 & 12.5 & 0.049 \\
\hline 2 & Double vessel disease (DVD) & 5 & 27.8 & 2 & 25.0 & $0.639^{\mathrm{N}}$ \\
\hline 3 & Triple vessel disease (TVD) & 1 & 5.5 & 3 & 37.5 & 0.072 \\
\hline
\end{tabular}

$\mathrm{p}$ value reached from fishers extact test

Table-VIII

Comparison of severity of coronary artery disease by Friesinger score between two age groups in relation to homocysteine level.

\begin{tabular}{|c|c|c|c|c|c|c|}
\hline \multicolumn{7}{|c|}{ Normal Homocysteine level $(\mathrm{n}=94)$} \\
\hline \multirow{2}{*}{\multicolumn{2}{|c|}{ Friesinger score }} & \multicolumn{2}{|c|}{ Group I $(n=42)$} & \multicolumn{2}{|c|}{ Group II $(\mathrm{n}=52)$} & \multirow[t]{2}{*}{ p Value } \\
\hline & & $\mathrm{N}$ & $\%$ & $\mathrm{~N}$ & $\%$ & \\
\hline \multicolumn{2}{|l|}{$0-4$} & 35 & 83.3 & 16 & 30.8 & \multirow[t]{2}{*}{0.001} \\
\hline \multicolumn{2}{|l|}{$\geq 5$} & 7 & 16.7 & 36 & 69.2 & \\
\hline \multicolumn{7}{|c|}{ High Homocysteine level $(n=26)$} \\
\hline & & \multicolumn{2}{|c|}{ Group I ( $\mathrm{n}=18)$} & \multicolumn{2}{|c|}{ Group II (n=8) } & \multirow[t]{2}{*}{$\mathrm{p}$ Value } \\
\hline & & $\mathrm{N}$ & $\overline{\%}$ & $\mathrm{~N}$ & $\%$ & \\
\hline $0-4$ & 7 & 38.9 & 4 & 50.0 & 0.457 & \\
\hline$\geq 5$ & 11 & 61.1 & 4 & 50.0 & & \\
\hline
\end{tabular}

$\mathrm{p}$ value reached from chi square test

\section{Discussion:}

Among the emerging risk factors, hyperhomocysteinemia is an independent risk factor for atherosclerotic disease. In a general population of elderly men, a high homocysteine level is common and is strongly associated with the prevalence of IHD and cerebrovascular disease. ${ }^{6}$ Folic acid and other B vitamins help break down homocysteine in the body. Recent studies show that homocysteine concentrations are higher in Indian Asians than European whites, and suggest that homocysteine may contribute to their increased mortality. These observations imply that the increased $\mathrm{CAD}$ in this racial group may be reduced by dietary supplementation with $\mathrm{B}$ vitamins. ${ }^{7}$ Cigarette smoking has been the single factor most strongly associated with CAD in the young adults. Younger, non-diabetics and smokers tend to have single-vessel disease. Diabetics and older population are more likely to have diffuse TVD. ${ }^{8}$ This study wanted to observe the effect of homocysteine on the angiographic profile of different age group patients.

In our study, male patients were more in both the groups. Similarly, Tewari et al. ${ }^{9}$ observed mean age sex ratio of the patients having $\mathrm{CAD}$, which closely resembles this study.

In this study, dyslipidemia was almost uniformly distributed in both groups. Smoking, hypertension, family history of IHD, high serum homocysteine were leading major risk factors for IHD in younger patient group. However, DM, hypertension and LVH were leading major risk factors in older patients. Schoenenberger et al. ${ }^{10}$ mentioned that smoking, family history of CAD, dyslipidemia are important cardiovascular risk factors in young patients. Tewari et $\mathrm{al}^{9}$ and Majumder et $\mathrm{al}^{11}$ also made similar observations. 
Mean BMI was found a little bit lower in younger than older group. Pradeep et $\mathrm{al}^{12}$ found similar BMI in their study. Tewari et $\mathrm{al}^{9}$ observed mean BMI in group-I and in group-II, similar to this study.

In our study, hyperhomocysteinemia came out as a risk factor for younger IHD group. Kawashiri et $\mathrm{al}^{13}$ reported that plasma homocysteine level of subjects in younger IHD group was significantly higher than that of subjects in older IHD group. Sadeghian et al. ${ }^{14}$ concluded that hyperhomocysteinemia is an independent risk factor for $\mathrm{CAD}$ in young especially in men.

In the present study, coronary angiogram of the study population showed that normal vessel and single vessel disease were more common in younger IHD patients. Whereas double vessel disease and triple vessel diseases were more significantly higher in older patients. Tewari et $\mathrm{al}^{9}$ showed in their study that SVD was more common in young patients and DVD \& TVD were more common elderly patients. Similar results were also evident in other studies. ${ }^{12,15}$

Regarding the involvement of vessels LM disease was not found in younger group but 3.3\% had LM disease in older group. Left anterior descending artery was the most commonly involved vessel followed by right coronary artery (RCA) and left circumflex artery (LCX) in both groups. Normal coronary arteries were more common in younger IHD patients. Pradeep et al ${ }^{14}$ also mentioned that left anterior descending artery (LAD) was the most commonly involved vessel followed by right coronary artery (RCA) and left circumflex artery (LCX) in both groups.

It was observed that as a whole Friesinger score 0 - 4 was predominant in younger patients. Friesinger score $\geq 5$ was predominent in older group. However regarding patients with higher serum homocysteine, Friesinger score $(\geq 5)$ was higher in group I than groups II. Bampi et al. observed that, Friesinger score $0-4$ indicates less extensive coronary artery disease and Friesinger score $\geq 5$ indicates extensive coronary atherosclerosis with extensive coronary artery disease. ${ }^{15}$

\section{Conclusion:}

In our study, it was observed that male gender, smoking, positive family history of IHD, and hyperhomocysenemia were significantly higher in younger age group. On the other hand, the prevalence of DM, hypertension and LVH were significantly higher in older age group. Normal, single vessels disease and less extensive disease were more common in younger group, and multivessel and extensive diseases were more common in older patients with IHD. However young patients with high serum homocysteine level had more multivessel disease and more severe CAD than older patients. So, raised serum homocysteine appears to be a potentially important risk factor for young IHD patients. This knowledge of the different profiles of risk factors and extent of CAD in two different age groups of Bangladeshi IHD patients will help us planning for both preventive and curative treatment strategy in future.

\section{Conflict of Interest - None.}

\section{References:}

1. Julian DG, Cowan JC, Mclenachan JM. Disease of the Coronary Arteries-Causes, Pathology And Prevention: Coronary Artery Disease. $8^{\text {th }}$ ed. New York: Elseiver Saunder ; 2005. 78-80.

2. Al-Khadra AH. Clinical profile of young patients with acute myocardial infarction in Saudi Arabia. Int $J$ Cardiol 2003; 91(1): 9-13.

3. Sricharan KN, Rajesh S, Meghana HCR, Badiger S, Mathew S. Study of Acute Myocardial infarction In young adults, Risk factors, Presentation and Angiographic Findings. Journal of Clinical and Diagnostic Research 2012; 6(2): 257-260.

4. Ismail J, Jafar FH, White F, Faruqui AM, Chaturvedi N. Risk factors for non-fatal myocardial infarction in young South Asian adults. Heart 2004; 90: 259-263.

5. Maron DJ, Rider PM, Grundy SM. Prevention Strategies for Coronary Heart Disease. In: Fuster V, Walsh RA, O'rourke RA, Wilson PP. Eds. Hurst's The Heart. 12 $2^{\text {th }}$ ed. Vol 1. New York, USA:Mc Graw Hill 2008; 1203-1244.

6. Stehouwer CDA, Weijenberg MP, van den Berg M, Jakob C. Serum Homocysteine and Risk of Coronary Heart Disease and Cerebrovascular Disease in Elderly Men. A 10 Year Follow-Up. Arterioscler Thromb Vasc Biol 1998;18: 189.

7. Chambers JC, Kooner JS. Homocysteine: a novel risk factor for Coronary heart disease in UK Indians Asians Heart. BMJ 2001;86:121-122,

8. Kumar N, Sharma S,Mohan B, Mohan B, Beri A, Aslam N, Sood N et al. Clinical and Angiographic Profile of patients presenting with First Acute Myocardial 
Infarction in a Tertiary Care Center in Northern India. Indian Heart Journal 2008; 60: 210-214.

9. Tewari S, Kumar S, Kapoor A, Singh U, Agarwal A, Bharti BB. Premature-coronary-artery disease in North India. An angiography study of 1971 patients. Indian Heart Journal 2005;57: 311-318.

10. Schoenenberger AW, Radovanovic D, Stauffer JC, Windecker S, Urban P, Niedemaier G. Acute coronary syndromes in young patients presentation, treatment and outcome. Int J Cardiol 2011, 148(3): 300-304.

11. Majumder AAS, Ali MA, Saha GK. Comparison of risk factor prevalence and complications between early onset and late onset acute myocardial infarction. Bangladesh Heart Journal 200; 15(2): 77-80.

12. Pradeep KN, Haritha PS, Krisman NR, Umesan CV, Joseph PK, Chandra K. Comparison of Coronary Artery Profile in Young and Old patients with coronary Artery
Disease and its Correlation with Coronary risk factors. Indian Heart Journal 2004;56:412.

13. Kawashiri M, Kajinami K, Nohara A, Yagi K, Inazu A, Koizumi J. Plasma homocysteine level and development of coronary artery disease. Coron artery Dis 1999;10(70):443-447.

14. Sadeghain S, Fallah F, Salarifar M, Davoodi G, Mahoodian M, Fallah N. Homocysteine, vitamin B12 and folate levels in premature coronary artery disease.BMC Cardiovascular Disoders 2006;6:38.

15. Khan AR, Islam AEM M, Ali M. Study of risk factors and coronary angiographic pattern in younger patients with acute coronary syndrome. Bangladesh Heart Journal 2004;19(.2):109-119.

16. Bampi ABA, Rochitee CE, Favarato D, Lemos PA, Luz PLD. Comparison of non-invasive methods for the detection of coronary atherosclerosis. Clinics (Sao Paulo). 2009;64(7):675-682. 